\title{
Biodiesel production from jatropha oil in a closed system
}

\author{
W. Shaaban ${ }^{1,2}$, A. H. El-Shazly ${ }^{1}$, M. F. Elkady ${ }^{1}$ and M. Ohshima ${ }^{3}$ \\ ${ }^{1}$ Chemical and Petrochemicals Engineering Department, Egypt-Japan University of Science and Technology, New Borg El-Arab City, \\ Alexandria, Egypt \\ ${ }^{2}$ Mechanical Power Engineering Department, Mansoura University, Egypt \\ ${ }^{3}$ Chemical Engineering Department, Kyoto University, Kyoto, Japan
}

\begin{abstract}
The use of biodiesel as an alternative fuel is becoming increasingly popular nowadays due to global energy shortage. The interest in using Jatropha as a non-edible oil feedstock is rapidly growing. Biodiesel produced from crude Jatropha oil with $\mathrm{NaOH}$ as a catalyst is investigated. Transesterification by methanol is carried out in a closed vessel as a batch system. Factors affecting the process which included the reaction temperature and pressure, reaction time, the molar ratio of methanol to oil and catalyst amount are investigated. The maximum conversion ratio of methyl ester yield of $97.7 \%$ was recorded under the conditions of $65^{\circ} \mathrm{C}, 1 \%$ (by mass) $\mathrm{NaOH}$ of the oil mass and $6: 1$ methanol to oil ratio.
\end{abstract}

\section{Introduction}

There is a growing enthusiasm for using renewable energies to reduce greenhouse effect as well as to reduce the dependence on petrol-based fuel because of the environmental, economic and supply troubles of fossil fuels [1]. Nowadays, when fossil fuel recourses are waning quickly, biodiesel fuels are turning out to be worthwhile. Biodiesel is a renewable and environmentally clean fuel for diesel engines [2]. Being environmentally beneficial, biodegradable, non-toxic and with low pollution emission makes biodiesel remarkable for utilization [3-5]. Distinctive ways have been accounted for biodiesel production such as microemulsification, pyrolysis, and transesterification [6]. The most widely recognized approach to delivering biodiesel is transesterification process, which refers to a catalyzed chemical reaction involving vegetable oil and alcohol to yield fatty acid alkyl esters (biodiesel) and glycerol as a by-product [6]. Methanol is the most usually utilized alcohol as a result of its low cost and its physicochemical advantages (polar compound and short chain alcohol) [7]. At the industrial scale, the alkaline catalyst is the most utilized because of its suitable operational conditions: low cost, simple to install and, above all, high reaction rate which gives a reduction in the equipment size [8].

Currently, edible oils are the main resources for world biodiesel production (more than 95\%) [9]. However, the broad utilization of edible oils may prompt some undesirable impacts such as starvation and higher food prices in developing countries [10]. Hence, non-edible plant oils turn out to be exceptionally encouraging option feedstock for biodiesel production [11]. Non-edible vegetable oils which are known as the second generation feedstocks can be considered as a promising alternative for traditional edible food crops for the production of biodiesel. However, as a serious drawback, most nonedible oils contain a high content of free fatty acids (FFAs), which increases the biodiesel production cost [12-14]. There are an enormous number of oil plants that deliver non-edible oils. From a list of 75 plant species containing oil in their seeds or kernels more than 30\%, 26 species were reported by Azam et al. [15] as potential sources of the oil that can be employed for the production of FAMEs suitable for the use as biodiesel. Jatropha curcas crude oil has been used for the biodiesel production [16]. Jatropha is a species of flowering plant in the spurge family, Euphorbiaceaea and it is a droughtresistant tree. It is a plant with numerous characteristics, different uses and extensive potential. The plant can be utilized to avoid and/or control disintegration, to recover area, developed as a live fence, especially to contain or exclude farm animals and be planted as a commercial crop. It is a native of tropical America, however now flourishes in numerous parts of the tropics and subtropics in Africa/Asia. It has few nuisances and diseases and will grow under a wide range of rainfall regimes from 200 to over $1500 \mathrm{~mm}$ per annum. In low rainfall areas and in delayed rainless periods, the plant sheds its leaves as a counter to dry spell [17].

Jatropha is easy to establish, grows relatively quickly and is hardy, being drought tolerant. It is not browsed, for its leaves and stems are poisonous to creatures, but after treatment, the seeds or seed cake could be used as a creature nourish. The oil from these seeds has low acidity, good oxidation stability, low viscosity and good cold properties [17]. Accordingly, this investigation was concentrated on the biodiesel production utilizing 
Egyptian Jatropha curcas crude oil (JCCO) in a closed vessel as a batch system.

\section{Experimental}

\subsection{Chemicals and materials}

\subsubsection{Chemicals}

Methanol with purity of $99.9 \%$ (Alpha Chemical Company, Egypt), acetic acid (Alpha Chemical Company, Egypt), Ethanol (Wako Pure Chemical Industries, Japan) and sodium hydroxide (Sigma-Aldrich Company, USA) were used without further purification. Freshly distilled water was used during the washing process. Ethanol was used for preparation of all produced biodiesel samples for gas chromatography analysis.

\subsubsection{Jatropha oil}

Jatropha curcas is a poisonous, semi-evergreen shrub or

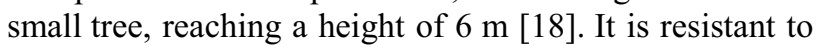
a high degree of aridity, allowing it to be grown in deserts. The fruits are produced in winter, or there may be several crops during the year if soil moisture is good and temperatures are sufficiently high. Most fruit production is concentrated from midsummer to late fall with variations in production peaks where some plants have two or three harvests and some produce continuously through the season. The fruit is oval-shaped ranging in length between 1-2 cm (Fig. 1) and every one contain from one to three seeds. the seeds are mature when the capsule changes from green to black as shown in Fig. 2. The seeds contain $27-40 \%$ oil [19] (average: $34.4 \%$ [20]) that can be processed to produce a highquality biodiesel fuel, usable in a standard diesel engine.

The crude material used in this work is acquired by getting the fruits of Jatropha from the trees growing in a governmental farm located in Luxor city (in upper Egypt) and squeezing the gathered seeds by a hydraulic piston. The residual particles in the oil are uprooted by filtration using $8 \mu \mathrm{m}$ filter paper under vacuum conditions. The separated oil is stored until the analysis of the oil composition and the biodiesel production procedures are performed (1 month).

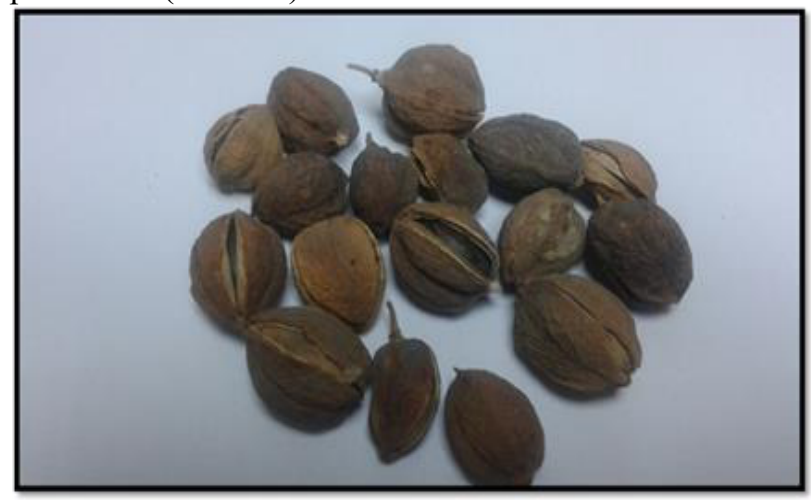

Figure 1. A photo of the Jatropha fruits.

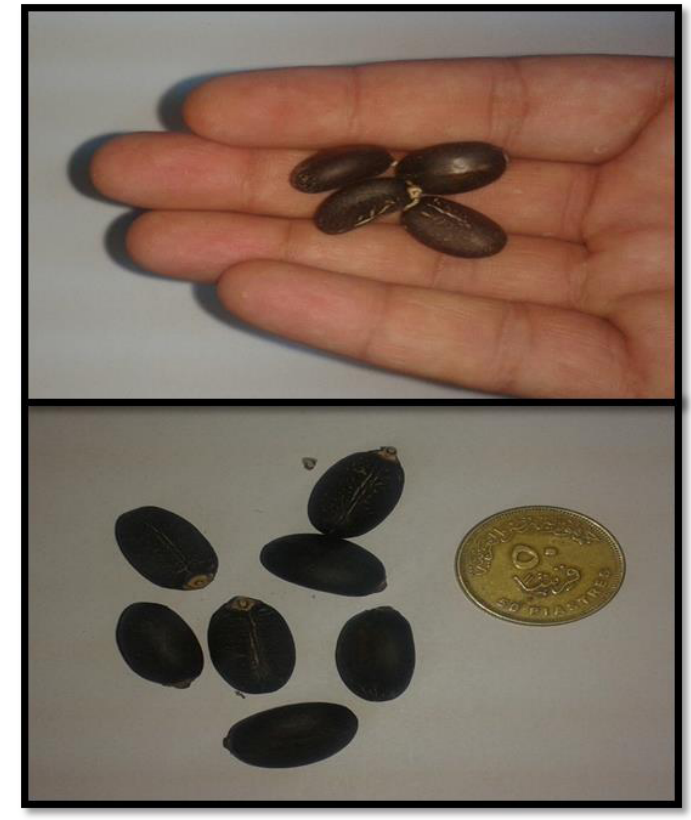

Figure 2. A photo of the Jatropha seeds.

\subsection{Biodiesel production process}

A schematic illustration of the experimental setup appears in Fig. 3 which utilized for transesterification reaction. The device is composed of a high-pressure stainless steel vessel (EV-3-50-2) of $50 \mathrm{ml}$ capacity as a closed batch reactor with pressure display (as shown in Fig. 4). This vessel is made from stainless steel 316 and has a maximum temperature and pressure limits of $100^{\circ} \mathrm{C}$ and $30 \mathrm{MPa}$, where the heating system consisted of a GC furnace. The amount of $\mathrm{NaOH}$ is dissolved in methanol then this was mixed with the oil in the closed vessel. The molar ratios of methanol to oil are adjusted from 4.5 to 9 . After a specific time, the reaction termination is done by addition of the acetic acid solution (20\%).

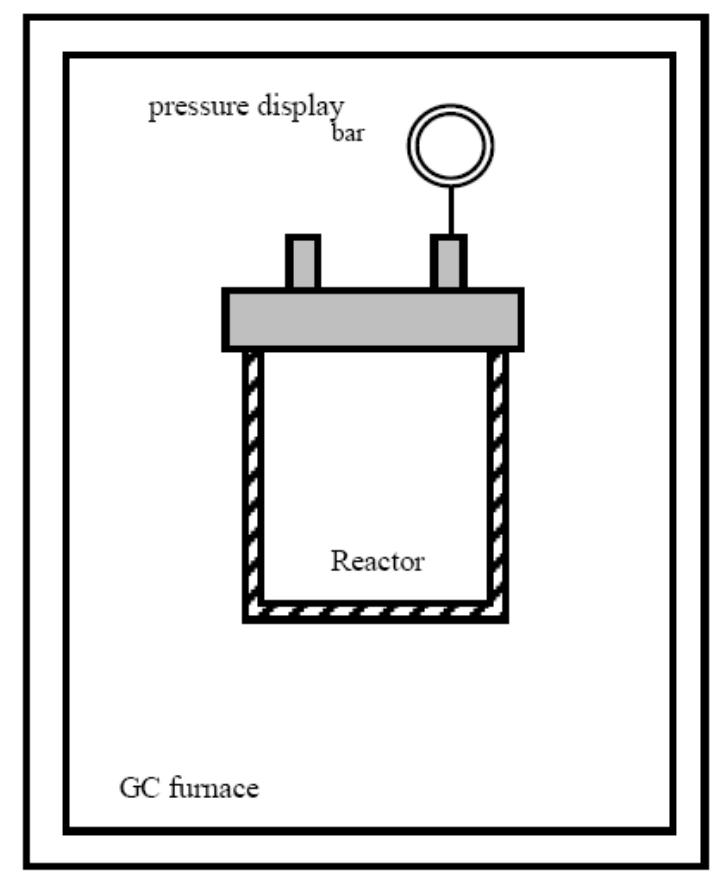

Figure 3. Experimental setup of the closed reactor. 
The collected product is then centrifuged at $5000 \mathrm{rpm}$ for $8 \mathrm{~min}$. The upper fatty acid methyl ester (FAME) layer is cleaned several times with distilled water to dismiss the remaining inorganic components. $1 \mathrm{ml}$ of the washed sample is mixed with $9 \mathrm{ml}$ of methanol then filtered through a syringe filter $(0.45 \mu \mathrm{m})$ to be analysed using a gas chromatography GC 2010 plus (AOC-20i).

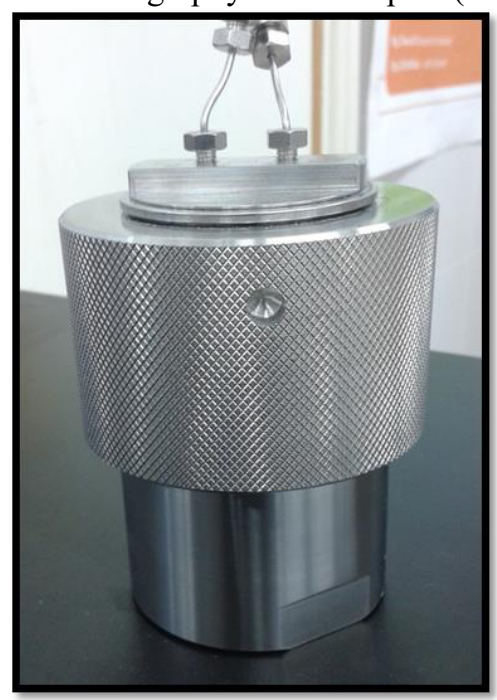

Figure 4. A photo for the pressure vessel.

\section{Result and discussion}

\subsection{Pressure-Temperature relation}

Fig. 5 represents the relation between the temperature and the obtained manometric pressure at two values of filling ratio which represents the ratio between the volume of the total reactants and the reactor which in turn leads to an increase in pressure. It is clear that there is a direct correlation between the reaction temperature and pressure generated.

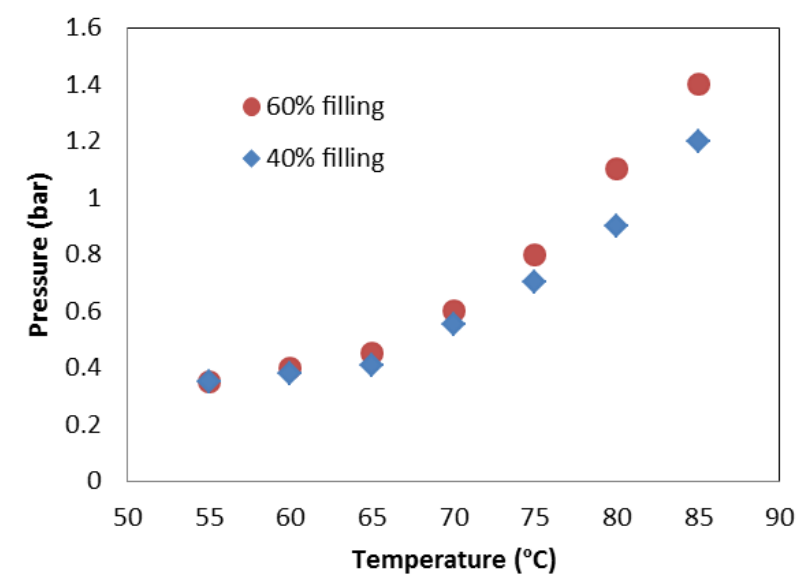

Figure 5. Relation between temperature and manometric pressure.

\subsection{Effect of molar ratio}

The theoretical methanol to oil ratio is $3: 1$ but higher molar proportion ought to be used to ensure that the reaction would be completed in light of the fact that transesterification reaction cannot be accomplished in that stoichiometric proportion. In this study, the molar ratio of methanol to oil is contrasted from 4.5 to 9 . The impact of the molar ratio of methanol to oil on the percentage of methyl esters conversion is established in Fig. 6. In this figure, every point is recognized with the mean percentage of methyl esters for all keeps runs at the same molar ratio.

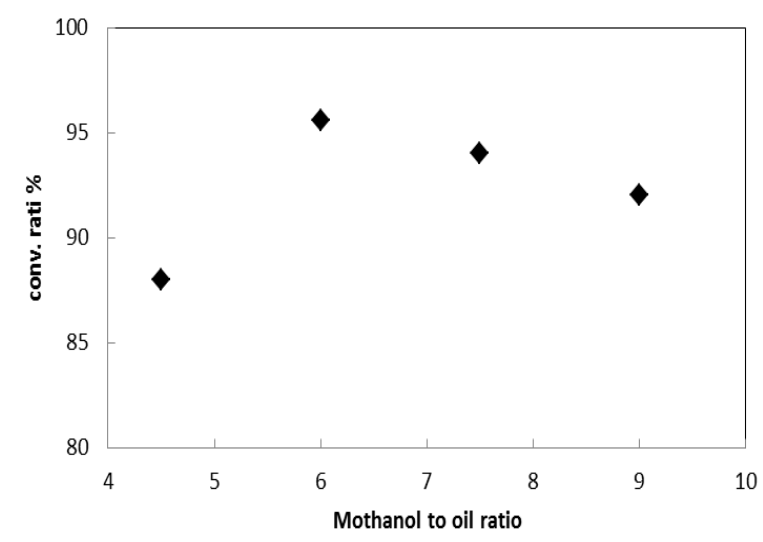

Figure 6. Effect of molar ratio on conversion ratio.

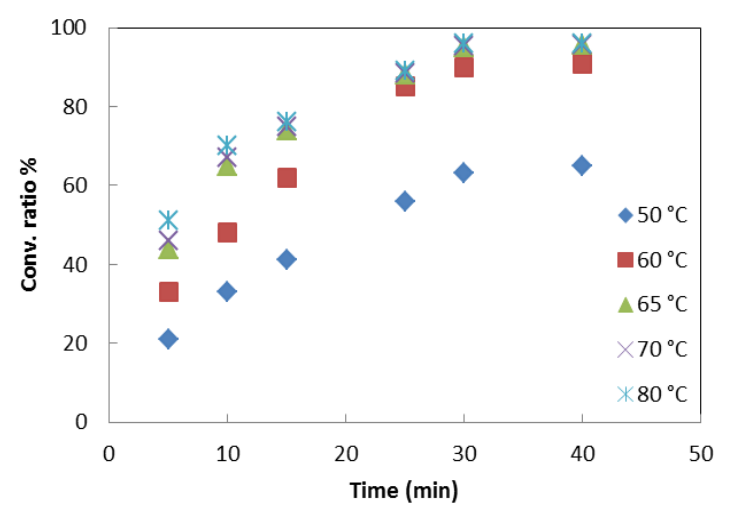

Figure 7. Effect of temperature on conversion ratio

The figure clarifies that the percentage of methyl esters expanded as the molar ratio of methanol expanded from 4.5:1 to $6: 1$. However, additional develop in the molar ratio of methanol from $6: 1$ to $9: 1$ brought about a slim lessening in the percentage of methyl esters. This behavior might be owed to the separation of glycerine and methyl ester. So, an extra molar ratio of methanol can diminish the percentage of produced methyl esters.

\subsection{Effect of reaction temperature}

The impact of the temperature on the percentage of methyl esters conversion is demonstrated in Fig. 7. The experiments are coordinated at reaction temperature range from 50 to $80{ }^{\circ} \mathrm{C}$ over residence time period from 5 to $40 \mathrm{~min}$. In this figure, every point affirms the Conversion ratio of methyl esters for all runs at the optimum conditions of molar ratio and the amount catalyst. It ought to be denoted that at low temperature, 
the reaction rate is slow and with expanding temperature, the percentage of methyl esters remarkably expanded.

The most extreme percentage of methyl esters for jatropha oil utilizing $\mathrm{NaOH}$ is done at $65^{\circ} \mathrm{C}$. On the other hand, as far as the temperature of the reaction is higher than the boiling point of methanol in typical pressure condition, a further increment in temperature to $70{ }^{\circ} \mathrm{C}$ caused the decline in the percentage of methyl esters. Furthermore, due to the high content of FFA in oil, increase in reaction temperature quickens the glycerides saponification by the alkaline catalyst.

\subsection{Effect of the reaction residence time}

The reaction time in biodiesel production is an exceptionally crucial parameter due to its role in the mass transfer between the two phases of reactants. Fig. 8 displays the effect of reactant residence time on the percentage of methyl esters conversion. The experiment is led at a temperature of $65^{\circ} \mathrm{C}, \mathrm{NaOH}$ amount of $1 \mathrm{Wt} . \%$ of the oil and a molar ratio (methanol/oil) of 6 . The outcomes assigned that percentage of methyl esters conversion expanded from $65 \%$ to $95.6 \%$ when the residence time is expanded from 10 to $40 \mathrm{~min}$. The percentage of methyl esters conversion change initially expanded to a great degree with expansion in residence time from 10 to $30 \mathrm{~s}$ and after that expanded marginally. The most extreme estimation of the methyl ester achieved very nearly $30 \mathrm{~min}$ and transesterification of oil is verging on complete. It can be observed that at residence time longer than 30min, the percentage of methyl esters conversion did not change eminently. Therefore, at the optimum condition with minimum residence time, a high percentage of methyl esters are accomplished with the most reduced biodiesel production cost.

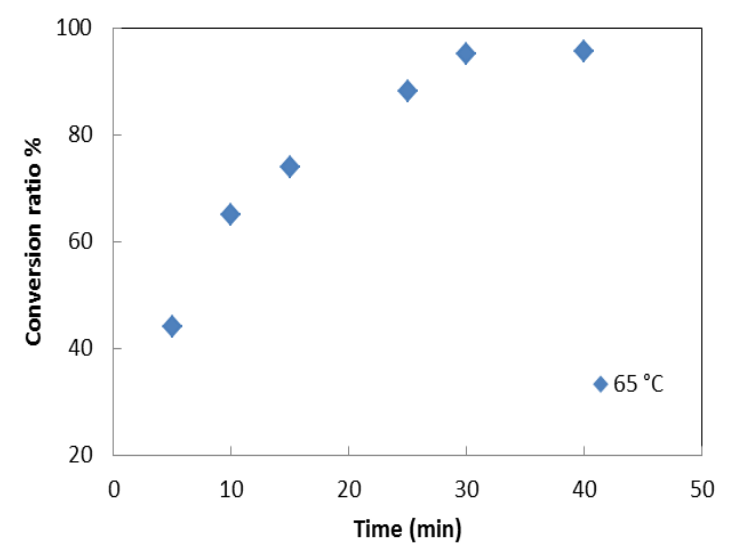

Figure 8. Effect of reaction residence time on conversion ratio

\subsection{Comparison between the closed and the open system}

Comparing the biodiesel production yield of Jatropha at closed and open system, it was found that the percentage of methyl esters conversion in the closed vessel is slightly better than that of the open vessel as shown in Fig. 9. May come to mind that the pressure plays a role in this increment, but as it known that increasing the pressure on a reaction involving only liquids has no effect on the rate.
So, keeping methanol from escaping, in the case of the open system, may be the well explains this improvement. Increasing the amount of methanol in the reaction region is exactly the same as increasing the methanol to oil ratio.

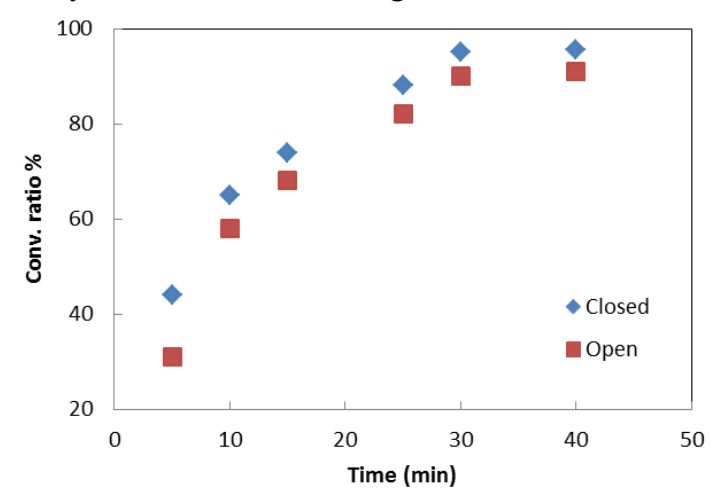

Figure 9. Comparison between the closed and the open system

\section{Conclusion}

The base catalyzed methanolysis of jatropha oil takes place at a closed vessel as a batch reactor. Factors affecting the process is studied and the highest conversion ratio of methyl esters conversion of $97.7 \%$ is obtained within 30min using 6:1 molar ratio of methanol to oil at the optimum conditions. It is shown that the yield of fatty acid ethyl esters depends strongly on mass transfer limitations. It is found that the maximum percentage of methyl esters for jatropha oil using $\mathrm{NaOH}$ is accomplished at $65^{\circ} \mathrm{C}$.

\section{Acknowledgment}

The author gratefully acknowledges the Egyptian ministry of agriculture which provided me by the Jatropha fruits. I want to thank and recognize the Egyptian ministry of higher education which granted a full Ph.D. scholarship and for Egypt-Japan University of Science and Technology (EJUST) and Japan International Cooperation Agency (JICA) for providing all the facilities to accomplish this work. In addition, I gratefully acknowledge all members of Department of Chemicals and Petrochemicals Engineering Lab for help and support.

\section{References}

1. M.F. Demirbas, M. Balat, Recent advances on the production and utilization trends of bio-fuels: a global perspective, Energy Convers Manage, 47(15), 2371-81 (2006)

2. N.N.A.N. Yusuf, S.K. Kamarudin, Z. Yaakub, Overview on the current trends in biodiesel production, Energy Conversion and Management, 52(7), 2741-51 (2011)

3. F. Ma, M.A. Hanna, Biodiesel production: a review, Bioresour Technol, 70 (1), 1-15 (1999)

4. S. Mekhilef, S. Siga, R. Saidur, A review on palm oil biodiesel as a source of renewable fuel, Renewable and Sustainable Energy Reviews,;15(4), 1937-49 (2011) 
5. M.E. Borges, L. Diaz, Recent developments on heterogeneous catalysts for biodiesel production by oil esterification and transesterification reactions: a review, Renewable and Sustainable Energy Reviews, 16(5), 2839-49 ( 2012)

6. Y. Zhang, M.A. Dubé, D.D. McLean, M. Kates, Biodiesel production from waste cooking oil: 1 . Process design and technological assessment, Bioresource Technol, 89, 1-16 (2003)

7. Stamenković, O.S., Veličković, A.V., Veljković, V.B., The production of biodiesel from vegetable oils by ethanolysis: current state and perspectives, Fuel 90, 3141-3155 (2011)

8. M. Berrios, M.A. Martin, A.F. Chica, A. Martin, Study of esterification and transesterification in biodiesel production from used frying oils in a closed system, Chemical Engineering Journal, 160, 473479 (2010)

9. Gui MM, Lee KT, Bhatia S., Feasibility of edible oil vs. non-edible oil vs. waste edible oil as biodiesel feedstock, Energy, 33, 1646-53 (2008)

10. Balat M., Potential alternatives to edible oils for biodiesel production-A review of current work, Energy Convers Manag, 52(2), 1479-92 (2011)

11. T.M. Yunuskhan, A.E. Atabani, Irfan Anjum Badruddin, Ahmad Badarudin, M.S. Khayoon, S. Triwahyono, Recent scenario and technologies to utilize non-edible oils for biodiesel production, Renewable and Sustainable Energy Reviews, 37, 840-851 (2014)

12. Leung DYC, Wu X, Leung MKH., A review on biodiesel production using catalyzed transesterification, Applied Energy, 87:, 1083-95 (2010)

13. Chhetri AB, Tango MS, Budge SM, Watts KC, Islam MR., Non-edible plant oils as new sources for biodiesel production, Int JMol Sci, 9(2), 169-80 (2008)

14. Koh MY, Mohd Ghazi TI., A review of biodiesel production from Jatropha curcas L oil, Renew Sustain Energy Rev, 15(5), 2240-51 (2011)

15. Azam MM, Waris A, Nahar NM., Prospects and potential of fatty acid methyl esters of some nontraditional seed oils for use as biodiesel in India, Biomass Bioenergy, 29, 293-302 (2005)

16. No SY., Inedible vegetable oils and their derivatives for alternative diesel fuels in CI engines: a review, Renew Sustain Energy Rev, 15, 131-49 ( 2011)

17. Keith Openshaw, A review of Jatropha curcas: an oil plant of unfulfilled promise, Biomass and Bioenergy, 19, 1-15 (2000)

18. Janick, Jules; Robert E. Paull (2008). The Encyclopedia of Fruit \& Nuts. CABI. pp. 371372. ISBN 978-0-85199-638-7.

19. Achten WMJ, Mathijs E, Verchot L, Singh VP, Aerts R, Muys B 2007. Jatropha biodiesel fueling sustainability? Biofuels, Bioproducts and Biorefining 1(4), 283-291.

20. Achten WMJ, Verchot L, Franken YJ, Mathijs E, Singh VP, Aerts R, Muys B 2008. Jatropha biodiesel production and use. (a literature review) Biomass and Bioenergy 32(12), 1063-1084. 